\title{
Open source photonics at the Abbe School of Photonics: How Makerspaces foster open innovation processes at universities
}

David Zakoth, Sabine Best, Reinhard Geiß, Christian Helgert, Peter Lutzke, et al.

David Zakoth, Sabine Best, Reinhard Geiß, Christian Helgert, Peter Lutzke, Oliver Mauroner, Thomas Pertsch, "Open source photonics at the Abbe School of Photonics: How Makerspaces foster open innovation processes at universities," Proc. SPIE 11143, Fifteenth Conference on Education and Training in Optics and Photonics: ETOP 2019, 111430G (2 July 2019); doi: $10.1117 / 12.2524615$ Photonics: ETOP 2019, 2019, Quebec City, Quebec, Canada 


\title{
Open Source Photonics at the Abbe School of Photonics: How Makerspaces foster Open Innovation Processes at Universities
}

\author{
David Zakoth ${ }^{\mathrm{a}}$, Sabine Best ${ }^{\mathrm{a}}$, Reinhard Geiß ${ }^{\mathrm{b}, \mathrm{c}^{*}}$, Christian Helgert $^{\mathrm{b}}$, Peter Lutzke ${ }^{\mathrm{d}}$, Oliver Mauroner, \\ and Thomas Pertsch ${ }^{\mathrm{b}, \mathrm{c}}$ \\ ${ }^{a}$ School of Business, University of Applied Sciences Mainz, Lucy-Hillebrand-Str. 2, 55128 Mainz, Germany \\ ${ }^{\mathrm{b}}$ Abbe Center of Photonics and Abbe School of Photonics, Friedrich Schiller University Jena, Albert-Einstein-Str. 6, 07745 Jena, Germany \\ ${ }^{\mathrm{c}}$ Institute of Applied Physics, Friedrich Schiller University Jena, Max-Wien Platz 1, 07743 Jena, Germany \\ ${ }^{\mathrm{d}}$ Fraunhofer Institute of Applied Optics and Precision Engineering, Albert-Einstein-Str. 9, 07745 Jena, Germany \\ * reinhard.geiss@uni-jena.de, Phone+49 3641 9-47965, www.acp.uni-jena.de and \\ www.lichtwerkstatt-jena.de
}

\begin{abstract}
The Abbe School of Photonics (ASP) provides photonics education of graduate and doctoral students at the Friedrich Schiller University in Jena, Germany. The main instrument for training students in optical sciences is a Master's degree program, which is open to international students, research-oriented and supported by German photonics industry. In this context, a conceptually new open lab Makerspace for photonics was established to support both the internal students in the realization of innovative and creative processes, as well as to build a strong and curious community of like-minded people from outside of the university. The photonics Makerspace provides all tools and materials needed to setup state-of-the-art optical instruments. Furthermore, it provides technical mentoring, open workshops and lectures. Partners from the photonics industry corroborate the process of making by well-established open innovation schemes and are integrated into the Makerspace with hackathon and innovation camp formats where the Makerspace users work on industry challenges. Finished and ongoing projects are transformed into freely accessible, open source hardware while a commercial exploitation of the projects is supported. Out of the broad topical spectrum of ongoing projects, two quite advanced examples are a low-cost smartphone-based 3D-scanner with a cloud-based, free software and a high-resolution microscope built of 3D-printed modules. For these projects, apart from hardware and software, also workshops and lectures are available. Other examples include a drone for medical applications in search and rescue, a smartphone-based lithography setup, a Raman-spectrometer, a camera array for meteorite detection, and many more. All activities of the Makerspace are scientifically investigated with special attention on the interaction between open innovation approaches and the Maker scene. Here, we will share our insights into potentials and opportunities offered by this novel educative approach.
\end{abstract}

Keywords: Open Photonics, Optics, Education, Open Source, Open Innovation, Makerspace, Maker Movement, Maker

\section{INTRODUCTION: UNIVERSITY MAKERSPACE FOR EDUCATION AND OPEN INNOVATION}

The region around Jena has a long tradition in the field of optics and photonics which goes back to the fundamental works of Ernst Abbe, Carl Zeiss and Otto Schott in the late $19^{\text {th }}$ century. Over the years, a very viable and competitive photonics cluster has evolved in that area of Germany. Nowadays, more than 15,800 jobs in industry and academia in that region are connected to photonics. ${ }^{1}$ Part of this viable ecosystem is also the Friedrich-Schiller University of Jena which is positioned as one of the leading educational centers in the field of optics and photonics.

In the year 2017 the university started to establish a Makerspace that has a specific focus on photonics to complement the education programs with a more hands-on approach. This aligns with the trend that recently more and more universities establishing Makerspaces. ${ }^{2}$ A Makerspace is a shared physical space where people can use digital fabrication tools like 3D printers, laser cutters, microcontrollers, and in this case also a fully equipped state-of-the-art optics laboratory, to 
experiment, build and share their knowledge with each other. ${ }^{3,4,5}$ The so-called "Lichtwerkstatt Jena - Open Photonics Makerspace" (Lichtwerkstatt is the German word for workshop) is located at the Abbe Center of Photonics and thereby integrated into the Abbe School of Photonics which enables easy access for university members, students, researchers of different disciplines and the maker community to use this ideation and experimentation space.

The Abbe School of Photonics (ASP) offers programs to educate in the broad spectrum of optical and photonics technology. The program covers state-of the art scientific aspects as well as engineering, with potential applications in areas such as information and communication technologies, medicine and health, manufacturing and energy consumption. ASP students are prepared for positions in both, industry and academic research.

The Master's degree and doctoral programs benefit from the experience in optics education having a long-lasting tradition at the Friedrich-Schiller University Jena. Optics and photonics are one of the university's key profile fields in education and research. The education programs of the Abbe School of Photonics are part of a modern research infrastructure belonging to the Abbe Center of Photonics. Through the Abbe Center of Photonics, the University interlinks with local research institutions such as the Fraunhofer Institute for Applied Optics and Precision Engineering, the Leibniz Institute of Photonic Technology, the Helmholtz Institute Jena and a number of prominent industrial partners

One of the main goals of the Makerspace is to deliver a hands-on experience to the participants and give them the opportunity to experiment, fail, learn and share experiences in a save learning environment during their studies before they hit the job market. An important part of the Lichtwerkstatt Jena - Open Photonics Makerspace concept is that it is not closed to be used only by university members but is following an open approach. This makes it also interesting for companies to get in contact with the Makerspace because more and more companies are recognizing that they have to open up their innovation processes and integrate external knowledge to stay competitive. ${ }^{6}$ Especially in the optics and photonics industry the establishment of open innovation practices is in discussion. ${ }^{7}$ This development aligns with the goal of the Makerspace to establish and foster open innovation processes within the photonics industry which on the other side supports the strategy of the Abbe Center of Photonics maintaining long-term relationships to major photonics and optics companies in Germany. The Makerspace at the Abbe Center of Photonics enables industry partners to establish open innovation processes by sharing innovation challenges with the highly educated and technically skilled users of the Makerspace, the so-called Makers (e.g. students, researchers, start-ups). For the companies the usage of a Makerspace is beneficial due to knowledge inflows from outside the company while for the Makers it is interesting to enrich their education by working on recent industry challenges, by getting access to exclusive technologies and by having direct access to possible employers.

The Makerspace receives funding from the Federal Ministry of Education and Research (BMBF). Three institutions are involved in the project: the Friedrich Schiller University Jena, the Fraunhofer Institute for Applied Optics and Precision Engineering and the University of Applied Sciences Mainz. While the first two institutions have expertise in the field of optics and photonics, the University of Applied Sciences Mainz complements the project with expertise in the fields of business management and human-centered-design methods to unleash the creative potential of the interdisciplinary teams who are working within the Makerspace.

\section{LICHTWERKSTATT JENA - OPEN PHOTONICS MAKERSPACE}

\subsection{Makerspace: Concept and Equipment}

The Lichtwerkstatt Jena - Open Photonics Makerspace offers anyone with an interest in the subject areas of photonics and optics free access to modern technical equipment and the necessary know-how for the development and realization of own ideas. Besides the fully equipped state-of-the-art optical laboratory, the Makerspace is equipped e.g. with different kinds of 3D printers (FDM and SLA), machines for laser material processing (laser cutter and laser marker), electronics, microcontrollers (e.g. Arduino, Raspberry Pi) and a fully equipped workshop.

\subsection{Target groups: Makers and Companies}

The target groups of the Lichtwerkstatt Jena are diverse and were identified through the accompanying research and constructive exchange with other Makerspaces. According to the goal of the Makerspace to link Makers and industry there are two main target audiences (1) creative Makers that come together with (2) companies who can open their innovation 
processes and enrich the company's knowledge base with new ideas and novel solutions through collaboration with Makers.

\subsubsection{Makers}

Makers are intrinsically motivated people who like to tinker with different digital fabrication technologies. ${ }^{3,4}$ The Makers that are targeted by the Lichtwerkstatt Makerspace are e.g. students, researchers, inventors, curious citizens, creative professionals, technicians, engineers or start-ups - the Lichtwerkstatt Jena aims at anyone who is interested in DIY, learning new things and wants to exchange with others:

a) Creative laymen: These include, in particular, creatives and physics enthusiasts who do not study either natural sciences or engineering. They enjoy DIY, are inspired by the possibilities of rapid prototyping and use optical systems to supplement their projects.

b) Professionals of tomorrow: undergraduate and graduate students in natural sciences or engineering that already have a high level of specialist abilities and a high thirst for new knowledge generation, even in specific areas of photonics and rapid prototyping. Their commitment is motivated by research-relevant and current problems.

c) Professionals of today: These are mostly employees or self-employed Makers who are working in the field of photonics or optics. They are familiar with current industry challenges and like to expand their specialist knowledge as well as implement their own ideas in the Makerspace.

d) Start-Ups: This target group is interested in founding a new company or is already in the start-up phase. They are looking for technical advice, support in the application of technology, physical space to implement their ideas or machines to build their first prototypes.

\subsubsection{Companies}

As described below the Makerspace is working tightly together with many companies within the photonics cluster around Jena, but it is also open to other companies. Finally, the company target group splits up into two subcategories:

a) Established companies: this target group uses the Makerspace to find new ideas outside of the company environment and get in contact with the creative innovation potential of Makers. They can use the Lichtwerkstatt Jena to develop new product ideas, to test alternative application scenarios for existing products, to present the brand in a creative environment or to find highly educated and experienced employees. Important to mention is that it can be both, established companies in the photonics industry, as well as off-branch companies, such as handcraft or media companies that can use the Makerspace.

b) Start-ups: this target group could be aligned to Makers when they use the Lichtwerkstatt Jena to produce their first prototypes, but they can also be companies who are giving a challenge into the Makerspace. In that case they are aligned to the target group of companies.

\subsection{Event Formats: Education and Community Building}

Due to the fact that the Makerspace was established as a top-down decision and did not evolve out of an already existing community it was important to build a sustainable community that is consistently using the Makerspace. To foster the community building the Lichtwerkstatt Jena team developed an educational program which starts with formats to inspire people to use the Makerspace and later get involved in more sophisticated formats where the participants build first prototypes to tackle current industry challenges. The following graph shows the formats used to build the viable community around the established Makerspace: 




Figure 1. Education formats offered by the Lichtwerkstatt Jena - Open Photonics Makerspace.

According to the individual knowledge level, in some of the education formats the participants could choose between the two stages "Basic" and "Pro": The "Basic" courses provide an introduction to a specific topic and are designed to be understood by everyone without prior knowledge. The "Pro" events aim at advanced participants who already have previous knowledge of the topic and would like to deepen their knowledge.

(a) Lectures: During the event, experts give an overview of the current state of science and technology, as well as current Makers of the Lichtwerkstatt Jena give an insight into their projects. The audience has the opportunity for questions and discussions. Lectures in particular aim to increase the awareness of the Lichtwerkstatt Jena, to give the participants a low-threshold access to the Makerspace to set impulses or inspiration for own project ideas.

(b) Workshops: Together with an expert, the participants develop application possibilities of specific technologies or procedures and use them directly in their own projects. In addition to just theoretical knowledge building the participants have the chance to enhance their knowledge with hands-on experience. Workshops aim to initiate and promote idea development and practical execution by the participants.

(c) Hackathons: The teams develop solutions to tackle current problems of science and industry partners. The challenge is to create concepts or demonstrators within a short specific timeframe e.g. 24 or 48 hours. At the end of the event the participants pitch their ideas. The goal is a result-oriented application of specific technologies for the creation of innovative concepts and demonstrators. This format is also used to initiate long-term projects for the Makerspace.

(d) Innovation Camps: This format is closely linked to the industry partners. In the collaboration project with companies, participants will be tasked with developing hardware and software-based solutions to current industry challenges. Within the multi-day event or the several-week processing phases, the teams develop ideas and tangible prototypes. In return, they gain access to exclusive technologies or data and work together with the companies. Depending on the tasks, topic-specific workshops are integrated into the format. Finally, the participants present their solutions in front of a specialist jury and the partner companies.

(e) OpenLab: The Makers have the opportunity to get to know and try out the technologies, procedures and materials of the Lichtwerkstatt Jena. The event offers space to exchange about experiences and to find suggestions for new joint projects. Mentors share their knowledge and assist with questions.

(f) Open Format: To stress the open character of the Makerspace approach the "open format" is a venue to experiment with different formats brought by industry or academia. For example, the University of Applied Sciences Mainz used this option to involve the Makerspace into an innovation seminar. The "Hands-on Innovation" seminar was held for business students at the University of Applied Sciences Mainz. The goal of the seminar was it to engage business students as Makers and provide them with basic knowledge in digital fabrication and photonics technologies such as LED-lighting or optical sensors to unleash their creative potential. In the course of the 3-month 3-hours per week 
seminar, the 32 business students had developed eight different ideas by using photonics technologies and the expertise provided by the Lichtwerkstatt Jena. The ideas showed a broad variety in terms of their innovative potential and in terms of technologies, e.g. one group of students built a carbon monoxide detecting lamp, others developed a smart mirror that could show weather forecasts and information about upcoming meetings, and finally another group formed an artistic LED-table for entertainment purposes.

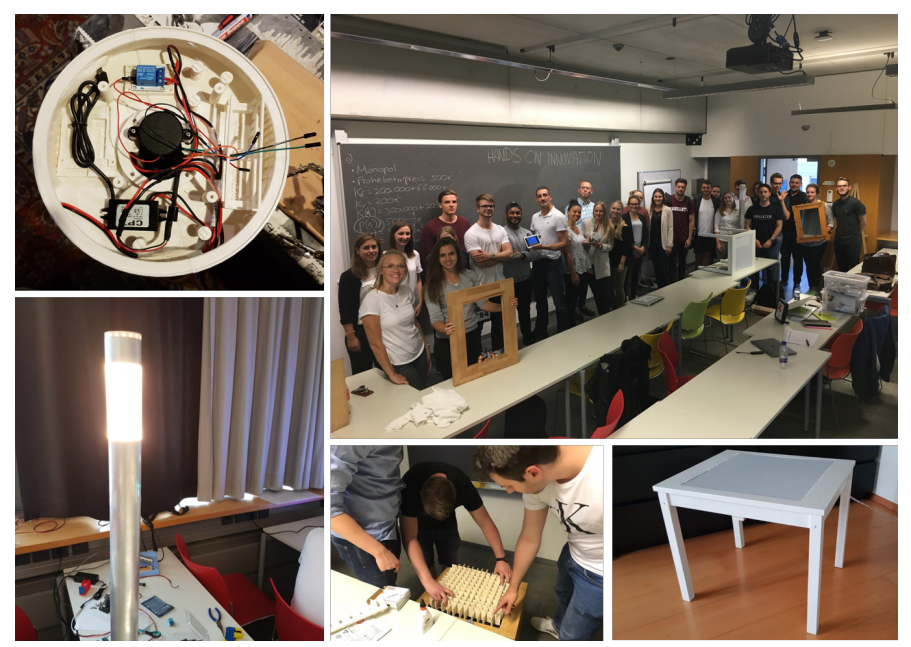

Figure 2. Impressions of the "Hands-on Innovation" seminar at the University of Applied Sciences Mainz involving the expertise of the Lichtwerkstatt Jena - Open Photonics Makerspace.

\section{RECENT MAKERSPACE OUTCOMES}

Due to the establishment of the above-mentioned event formats more and more projects are evolving in the Lichtwerkstatt Jena. The Makerspace supports different kind of projects which are started by students, researchers and other Makers e.g. an open source single pixel camera project or a project which investigates the possibility to use smartphones for lithography and a medical drone which uses photonics technologies to offer an improved first aid service in areas which are hard to reach with existing solutions. In this section, two recently nurtured Makerspace projects are described in more detail to give a short impression what the Makerspace is used for and what can evolve out of an University Makerspace and the Maker community.

1) UC2 - a modular photonics toolbox:

The open source modular toolbox for rapid prototyping in the field of optics is based on 3D-printed cubes that have magnetic connectors making them easy and fast to adapt to a variety of different applications. This idea enables to make standard optical assemblies for training students. More impressively, it can be used realize modern high-resolution microscopy technologies by using the camera of a smartphone. Two PhD students initiated the project, they decided to use the Makerspace and the established Maker community to develop and improve their idea. All parts can be 3D-printed or are consumables which are easily available over online distributors. More about the project: www.useetoo.org. 


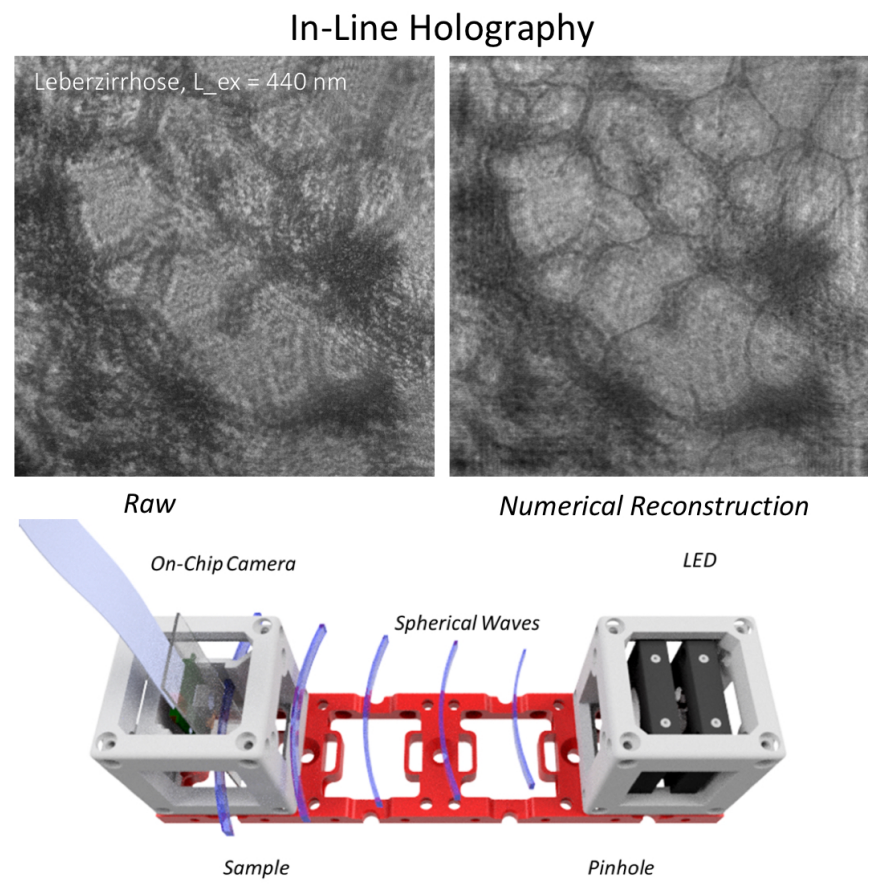

Figure 3. Concept of the in-line holography microscope based on the UC2 modular microscope system. (source: https://github.com/bionanoimaging/UC2-GIT)

\section{2) Fraunhofer IOF - low-cost 3d capturing development kit}

The Fraunhofer Institute for Applied Optics and Precision Engineering (IOF) is developing an easily accessible development kit for flexible low-cost 3D sensor technology with pattern projection within the Makerspace. Scientists are helping the Maker community implementing this kit in innovative prototypes. As a carrier platform for data acquisition and utilization, marketable systems such as mobile phones or tablets are used. The necessary software is made available for use and further development via the respective app stores of the Maker Community.

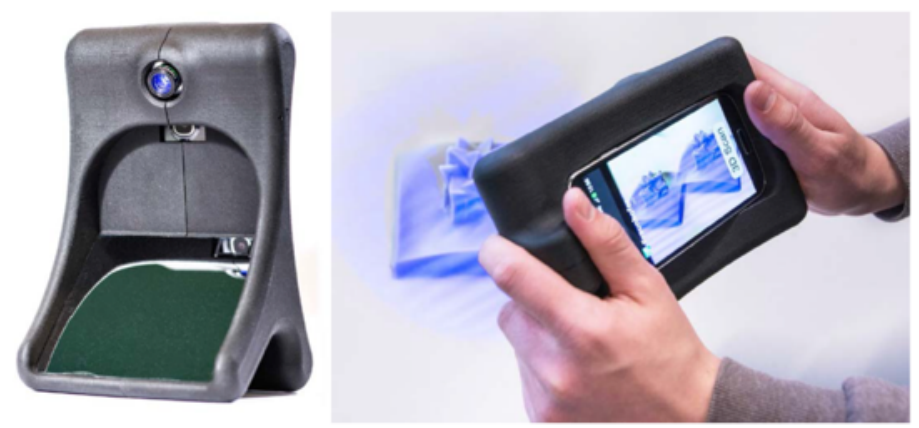

Figure 4. Design prototype of the Fraunhofer IOF low-cost 3d capturing development-kit (source: Fraunhofer IOF)

\section{BENEFITS OF AN UNIVERSITY MAKERSPACE}

The establishment of an University Makerspace seems to be a first step to give university members like students, $\mathrm{PhD}$ students, Post-Docs etc. the possibility to transfer their ideas into prototypes or products and thereby to transfer intellectual property generated in the universities to the marketplace easier. Use of the Makerspace is not limited to those working within the university. The space is also a place where external knowledge migrates back to the university e.g., when used by established companies, start-ups or people who are just interested in photonics. 
In this sense, a Makerspace can be an opportunity to engage knowledge flows in and out of academic institutions which aligns with the idea of open innovation. ${ }^{6}$ The effect of a University Makerspace would be even stronger if it is understood as a complementary education and rapid-prototyping service. In this sense, it should be well connected to the curriculum and other university services offered by the university entrepreneurship centers, for example. One recent observation at the Abbe Center of Photonics is that more and more scientists use the Makerspace for rapid prototyping of parts needed for their optical laboratory experiments. In this way, the needed parts undergo different design iterations very quickly and, thus, avoid long delivery or manufacturing times. Furthermore, to facilitate the transition from research to the industry as well as support start-ups the Friedrich-Schiller University Jena and the Fraunhofer IOF have established the Digital Innovation Hub Photonics (DIHP) just close by the Lichtwerkstatt Jena. The DIHP complements the offerings of the Makerspace (www.innohub-photonics.de) by offering different services to foster the innovation culture in the photonics industry e.g. by supporting start-ups in the process of establishing strategic partnerships with photonics companies and thereby accelerate the growth and time to market for the new ventures. Figure 5 summarizes some of the benefits achieved through the establishment of an University Makerspace.

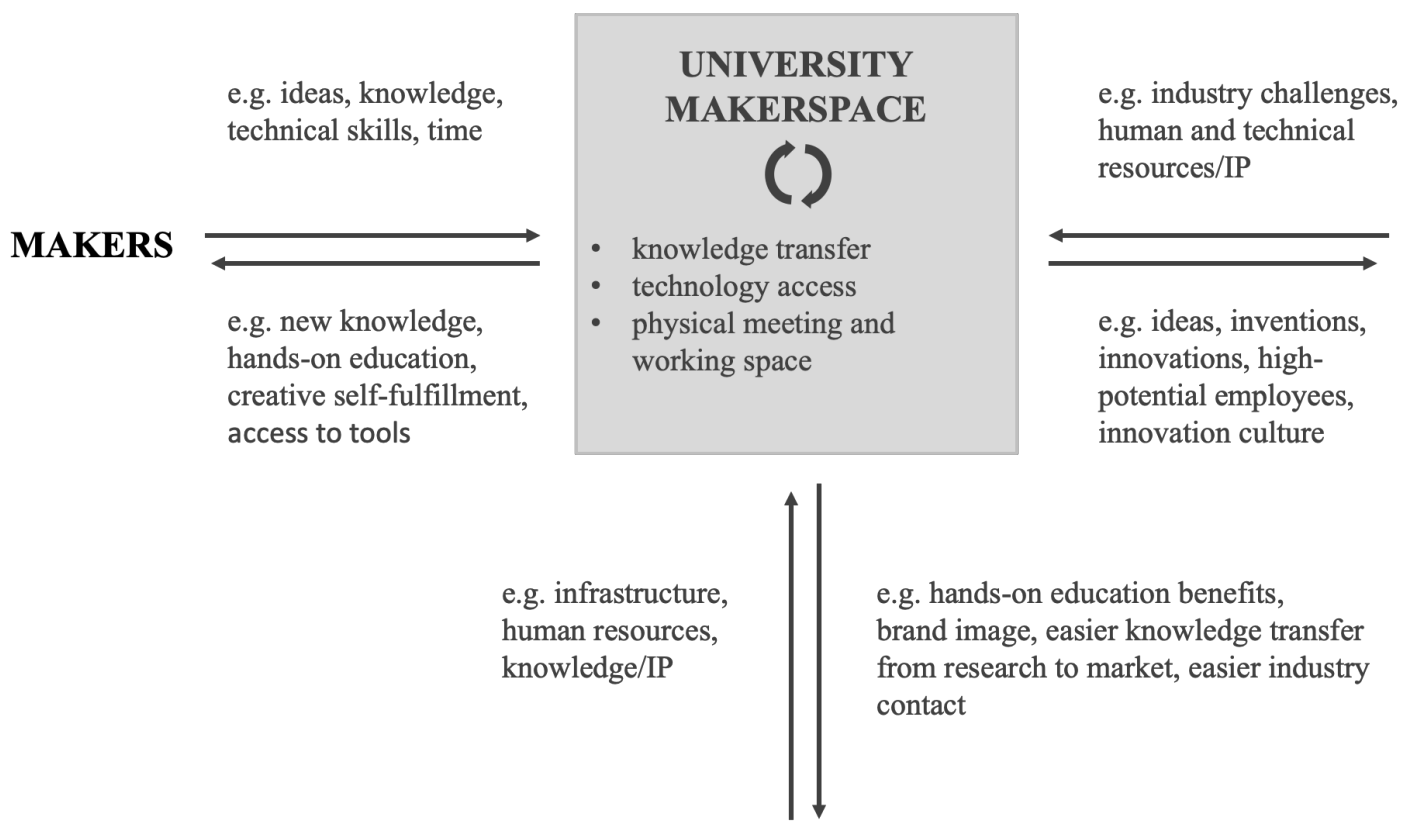

\section{UNIVERSITY}

Figure 5. Benefits of an University Makerspace by different stakeholders.

\section{ACKNOWLEDGEMENTS}

The authors wish to acknowledge the financial support by the German Federal Ministry of Education and Research (BMBF) through the funding scheme "Open Photonik" which enables the "Open Photonik Innovationsprozesse in der Licht-Region Jena (Lichtwerkstatt)" project.

\section{REFERENCES}

[1] OptoNet (2017). “Photonics Report 2017,” Jena: OptoNet e.V.

[2] Barrett, T. W., Pizzico, M. C., Levy, B., Nagel, R. L., Linsey, J. S., Talley, K. G., Forest, C. R., and Newstetter, W. C. (2015). "A Review of University Maker Spaces," in Proceeding of 2015 ASEE Annual Conference \& Exposition, June 14-17, Seattle, WA. 
[3] Gershenfeld, N. (2005). "Fab: the coming revolution on your desktop - from personal computers to personal fabrication," New York: Basic Books.

[4] Anderson, C. 2012. "Makers: The New Industrial Revolution," Crown Business.

[5] Mauroner, O. (2017). "Makers, hackers, DIY-innovation, and the strive for entrepreneurial opportunities," International Journal for Entrepreneurship and Small Business, Vol. 31, No 1, p. 32-46.

[6] Chesbrough, H. (2003). "Open Innovation: The new imperative for creating and profiting from technology," Boston: Harvard Business School Press.

[7] Chesbrough, H., and Eichenholz, J. (2013). "Open innovation in photonics," SPIE Professional, Vol. 8, p. 2425. 